\title{
A Recycling Defect as a Characteristic of Natural Killer Cells in Childhood Acute Lymphoblastic Leukemia
}

\author{
AKIHIKO YABUHARA AND HIROSHI KAWAI \\ Department of Pediatrics, Shinshu University School of Medicine, Matsumoto, Japan
}

\begin{abstract}
The cytolytic function of natural killer (NK) cells and their responsiveness to interferon- $\alpha$ and IL-2 were investigated in children with acute lymphoblastic leukemia (ALL) using ${ }^{51} \mathrm{Cr}$-release and single-cell assays. For comparison, such NK cell functions were similarly assayed in neuroblastoma. NK activity in ALL children was extremely low at onset, but it increased gradually during remission and finally reached normal levels. At the single-cell level, their NK cells at onset were defective in the binding, lytic, and recycling abilities. Although the binding and lytic defects improved to normal levels during remission, the recycling, which increased gradually during remission, was still low even after the long-term remission in ALL: the maximal recycling capacity values were $1.9 \pm$ $0.4(p<0.001)$ at onset and $4.6 \pm 0.6(p<0.05)$ after 5 $y$ of complete remission, as compared to the value in control children of $5.4 \pm 0.7$. On the other hand, children with neuroblastoma had no recycling defect after completing the therapy: their maximal recycling capacity value was $5.6 \pm$ 0.7. Bone marrow cells in ALL were also depressed in their recycling ability at all stages. Interferon- $\alpha$ and IL-2 could enhance NK activity and IL-2 could generate lymphokine-activated killer activity at all stages of $A L L$; however, the recycling defect hardly improved with these treatments. Thus, NK cells in childhood ALL have a recycling defect as a functional characteristic. (Pediatr Res 28: 572-578, 1990)
\end{abstract}

\section{Abbreviations}

NK, natural killer

ALL, acute lymphoblastic leukemia

IFN, interferon

LAK, lymphokine-activated killer

$\mathrm{PB}$, peripheral blood

PBL, peripheral blood lymphocyte

BMC, bone marrow cell

E:T, effector: target

TBC, target-binding cell

DC, dead conjugate

MRC, maximal recycling capacity

LU, lytic unit

NK cells have been described as cells capable of lysing tumor and virus-infected cells $(1,2)$. Leukemic cells appear to be particularly sensitive to NK lysis $(2,3)$, suggesting the importance of NK cells in the defense against leukemia. Indeed, individuals

Received March 30, 1990; accepted July 26, 1990.

Correspondence: Dr. Akihiko Yabuhara, Department of Pediatrics, Shinshu University School of Medicine, Asahi 3-1-1, Matsumoto, 390, Japan. with NK deficiency exhibit higher susceptibility to leukemia and lymphoma $(4,5)$. Considering the role of NK cells in leukemogenesis, it is noteworthy that leukemia patients have low NK activity (3, 6-9).

NK cell cytolytic mechanisms consist of several steps (10): recognition, binding, lysis, and recycling. Previous studies on the mechanisms have revealed different types of NK cell impairment (5, 11-13). A single-cell assay allows the estimation of binding, lytic, and recycling abilities of NK cells and the determination of numbers of cytotoxic NK cells $(10,14)$. By using it, Lotzová et al. (3) have demonstrated that NK cells in adult leukemia have multiple defects in the cytolytic mechanisms at the time of onset.

Cytokines such as IFN and IL-2 are potent activators of NK cells $(2,4,7)$, and LAK cells, which are generated mainly from NK cells by the incubation with IL-2 (15), are able to lyse autologous leukemic cells $(3,16)$. Thus, these cytokines may be therapeutically useful for preventing the relapse and spread of leukemia or for reducing the number of leukemic cells resistant to cytotoxic agents.

In our study, we investigated the mechanism(s) of impaired NK cytotixicity in children with ALL and responsiveness to IFN$\alpha$ and IL-2 of their NK cells using a single-cell assay. To characterize NK cells in ALL, we performed these investigations in neuroblastoma as well.

\section{MATERIALS AND METHODS}

Patients. Forty-three ALL children, ranging in age from 2 to $15 \mathrm{y}$, were included in this study. The diagnosis of leukemia was made based on the morphologic features and surface markers of leukemic cells. Fourteen patients were studied at onset; they had less than $5 \%$ of leukemic cells in the PB. Twenty-nine patients, including the patients studied at onset, were examined one to three times during the maintenance therapy; they were divided into three groups based on the remission duration $(<2 \mathrm{mo}, 2-12$ mo, and 12-36 mo). Sixteen off-therapy patients were also examined and divided into two groups based on the duration of off-therapy periods $(<2$ y and $>2$ y). Five relapsed patients without leukemic cells in the PB were studied; four of them were examined after 2 mo of the second remission.

Newly diagnosed ALL children received the remission induction and maintenance therapies on the Tokyo Children's Leukemia Study Group treatment schedule. Briefly, the induction therapy consisted of prednisolone, vincristine, and L-asparaginase. After attaining complete remission, the patients were placed on the maintenance therapy with 6-mercaptopurine and methotrexate. The therapy was discontinued after $3 \mathrm{y}$ of complete remission. When bone marrow relapse occurred, the patients were treated with combinations of several cytotoxic drugs.

For comparison, 20 children with stage I to IV neuroblastoma, ranging in age from 6 mo to $7 \mathrm{y}$, were studied. All of them were histologically diagnosed and treated with combinations of 
chemotherapy, surgery, and irradiation. Control subjects included 27 healthy adult volunteers, ranging in age from 21 to 30 $\mathrm{y}$, and 25 children, ranging in age from 6 mo to $15 \mathrm{y}$. These children visited our hospital for examination for hematologic or immunologic disorders, but were proved to be free.

Surface marker analysis. To evaluate the number of cells with NK-related phenotypes in PB, surface markers of lymphocytes were analyzed in an EPICS V flow cytometer (Coulter Electronics, Hialeah, FL) using FITC-conjugated anti-Leu-7, anti-Leu1 la (Becton Dickinson, Parsippany, NJ), and phycoerythrinconjugated NKH-1 (Coulter Immunology, Hialeah, FL) MAb. The absolute numbers of NK-related antigen-positive cells were estimated by multiplying their percentages by the total number of lymphocytes.

Preparation of effector cells. Mononuclear cells were separated from the heparinized venous blood by centrifugation on a FicollHypaque gradient and depleted of monocytes by adherence on a plastic surface. The nonadherent mononuclear cells were resuspended in RPMI-1640 medium with $10 \%$ heat-inactivated FCS and used as PBL. Bone marrow mononuclear cells were similarly obtained from the heparinized samples of bone marrow and used as BMC. For assaying NK cytotoxicity, PBL $\left(1 \times 10^{6} /\right.$ $\mathrm{mL}$ ) were incubated for $24 \mathrm{~h}$ in a humid atmosphere of $5 \% \mathrm{CO}_{2}$ at $37^{\circ} \mathrm{C}$ with medium alone, $1000 \mathrm{U} / \mathrm{mL}$ IFN- $\alpha$ (Kyowa Hakko Co., Tokyo, Japan), or $200 \mathrm{U} / \mathrm{mL}$ recombinant IL-2 (Takeda Seiyaku Co., Osaka, Japan). Likewise, BMC $\left(1 \times 10^{6} / \mathrm{mL}\right)$ were incubated for $24 \mathrm{~h}$ with medium alone. LAK cells were induced by culturing PBL $\left(1 \times 10^{6} / \mathrm{mL}\right)$ with $200 \mathrm{U} / \mathrm{mL}$ recombinant IL-2 for 1,3 , and $5 \mathrm{~d}$. After the incubation, these cells were washed once and used as effector cells.

${ }^{51} \mathrm{Cr}$-release assay. NK activity was determined in a $4-\mathrm{h}{ }^{51} \mathrm{Cr}-$ release assay using $\mathrm{K} 562$ target cells as previously described (12, 14). Briefly, effector cells were mixed with ${ }^{51} \mathrm{Cr}$-labeled $\mathrm{K} 562$ cells $\left(1 \times 10^{4}\right)$ in a total volume of $200 \mu \mathrm{L}$ in the wells of roundbottomed microtiter plates (Nunc, Roskilde, Denmark); E:T ratios varied from 40:1 to $2.5: 1$ depending on the effector cells tested. The cell mixtures were incubated for $4 \mathrm{~h}$ at $37^{\circ} \mathrm{C}$ in a $5 \%$ $\mathrm{CO}_{2}$ atmosphere. After the incubation, the plates were centrifuged, and $100 \mu \mathrm{L}$ of the supernatant were harvested and assayed for radioactivity. Percent cytotoxicity was calculated by the following formula: \% cytotoxicity $=[$ (experimental release - spontaneous release)/(total release - spontaneous release)] $\times 100$. $\mathrm{NK}$ activity was expressed as LU $/ 10^{6}$ cells (a LU was defined as the number of effector cells required for $20 \%$ lysis). LAK activity was similarly determined in a 4-h ${ }^{51} \mathrm{Cr}$-release assay using Raji target cells and expressed as $20 \% \mathrm{LU} / 10^{6}$ cells.

Single-cell cytotoxicity assay in agarose. This assay was performed as described in our earlier study (14). Briefly, equal numbers of effector cells and unlabeled K562 or Raji target cells $\left(2 \times 10^{5}\right)$ were mixed in a total volume of $200 \mu \mathrm{L}$ RPMI-1640 with $10 \%$ FCS, centrifuged at $250 \times g$ for $5 \mathrm{~min}$, and incubated at $37^{\circ} \mathrm{C}$ for $10 \mathrm{~min}$. The resulting pellet was gently resuspended, and then the resuspended cells were added to $0.5 \%$ agarose in RPMI-1640, which had been maintained in liquid form at $39^{\circ} \mathrm{C}$. The cells were mixed and immediately poured onto culture plates. After solidifying, the plates were incubated at $37^{\circ} \mathrm{C}$ for 4 $\mathrm{h}$ (in some experiments for $0.5,1,2,4$, and $8 \mathrm{~h}$ ) and then stained with $0.1 \%$ trypan blue. Control plates of target cells alone were prepared in the same way.

The plates were examined under a microscope. The $\%$ TBC was determined by counting the number of lymphocytes bound to target cells in more than 400 lymphocytes. The percentage of dead target cells in conjugates was determined by counting the number of trypan blue-positive target cells in 100 conjugates. The percentage of spontaneously dead target cells was determined by counting the number of trypan blue-positive cells in 100 target cells on control plates. Then, a correction was made using the following formula to calculate the $\% \mathrm{DC}: \% \mathrm{DC}=$ (percentages of dead target cells in conjugates) - (percentage of spontaneously dead target cells) $\times$ (percentage of dead target cells in conjugates). The percentage of cytotoxic cells, which have both binding and lytic abilities against K562 or Raji cells, was estimated by multiplying \% TBC by \% DC. When lymphocytes were untreated, the cells cytotoxic against K562 cells were defined as cytotoxic NK cells.

Estimation of $V_{\max }$ and $M R C$. Maximal cytolytic potential $\left(\mathrm{V}_{\max }\right)$ of effector cells and their recycling capacity were determined by combining data from ${ }^{51} \mathrm{Cr}$-release and single-cell assays as described in our previous report (14). Briefly, $V_{\max }$ values were determined on the basis of Michaelis-Menten enzyme-substrate kinetics. These values were found to correlate well with the values of $\%$ cytotoxicity from a ${ }^{51} \mathrm{Cr}$-release assay at a 5:1 E:T ratio: when NK and LAK cytotoxicities of PBL and NK cytotoxicity of BMC were examined, the correlation coefficients between the two values were $0.96,0.95$, and 0.93 , respectively. It was thus possible to get rough estimation of $\mathrm{V}_{\max }$ values by using the ${ }^{51} \mathrm{Cr}$-release assay. In our present study, $V_{\max }$ values were calculated using the following formula: $\mathrm{V}_{\max }=1.9 \times 10^{3}+$ $4.0 \times 10^{2} \times(\%$ cytotoxicity at an E:T ratio of 5:1). MRC, which represents the average number of target cells killed by each cytotoxic cell in $4 \mathrm{~h}$, was estimated by dividing $\mathrm{V}_{\max }$ by the absolute number of cytotoxic cells among $10^{5}$ effector cells.

Statistical analysis. Comparisons were done using $t$ test and correlations were computed using linear regression analysis by the least squares method.

\section{RESULTS}

Percentages and absolute numbers of NK-related antigen-positive cells. To evaluate the number of NK cells in childhood ALL, immunophenotypic analysis of lymphocytes was performed (Table 1). At all stages of ALL, the percentages of CD16(Leu-11a) ${ }^{+}, \mathrm{CD} 56(\mathrm{NKH}-1)^{+}$, and CD57(Leu-7) $)^{+}$cells were similar to those of control children. However, the absolute numbers of these cells were low at the active stages (onset and relapse) and the early stage of complete remission, indicating that ALL children have a quantitative deficit in NK cells only at these stages.

NK activity of PBL. As shown in Figure 1 and Table 2, ALL children had extremely low NK activity at onset. After achieving complete remission, their NK activity increased with time despite receiving the maintenance therapy. After completing the therapy, an additional increase in NK activity was observed; however, the values of $\mathrm{NK}$ activity remained low for the first $2 \mathrm{y}$ as compared to those in control children. When relapsed, NK activity was lower than that at onset; it then increased only slightly during the second remission.

Neuroblastoma children had also low NK activity at onset: the values were lower in the patients with bone marrow involvement. However, after the active stage, their NK activity almost reached control levels even if they were receiving chemotherapy.

When PBL were treated with IFN- $\alpha$ or IL-2, NK activity was enhanced at all stages of ALL (Fig. 1). The resulting activity, i.e. IFN- $\alpha$ - or IL-2-activated NK activity, showed the same pattern as endogenous NK activity: it was extremely low at onset but increased gradually during complete remission. On the other hand, in neuroblastoma, IFN- $\alpha$ - and IL-2-activated NK activities were slightly low at onset as compared to those of control children, but reached control levels after the active stage (data not shown).

NK parameters of PBL. The results are shown in Table 2. Newly diagnosed ALL children had depressed values for $\%$ TBC at the time of onset and the early stage of the maintenance, but the values reached control levels thereafter. As for \% DC and \% cytotoxic NK cells, these values became normal after cessation of the maintenance therapy. In contrast to these parameters, MRC, which increased gradually during complete remission, remained low even after the long-term remission. After relapse, the NK functions were more severely depressed: most of the 
Table 1. Percentages and absolute numbers of NK-related antigen-positive cells in peripheral blood

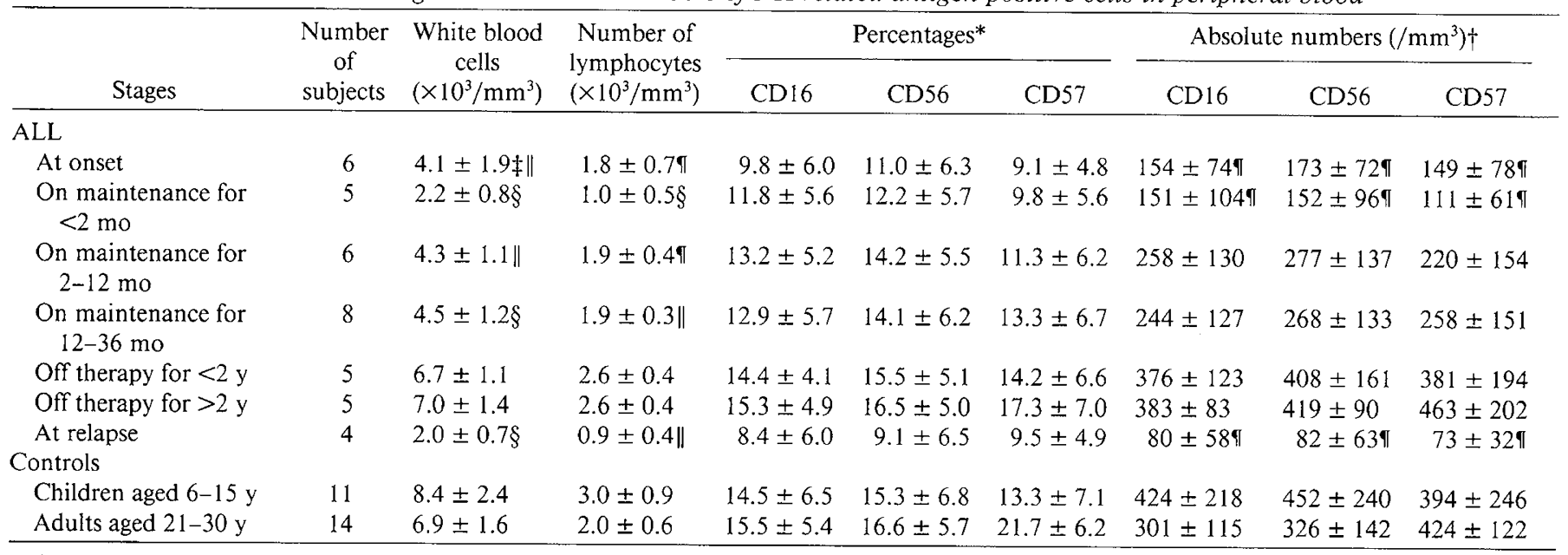

* The percentages of NK-related antigen-positive cells were determined by an EPICS V flow cytometer (Coulter Electronics) using FITC-conjugated anti-Leu-7 and anti-Leu-1 1 a (Becton Dickinson), and phycoerythrin-conjugated NKH-1 (Coulter Immunology) MAb.

$\dagger$ The absolute number of NK-related antigen-positive cells was estimated by multiplying their percentage by the corresponding total number of lymphocytes.

$¥$ Results are expressed as mean $\pm \mathrm{SD}$.

$\S p<0.001$ as compared to values of control children.

$\| p<0.01$ as compared to values of control children.

If $p<0.05$ as compared to values of control children.

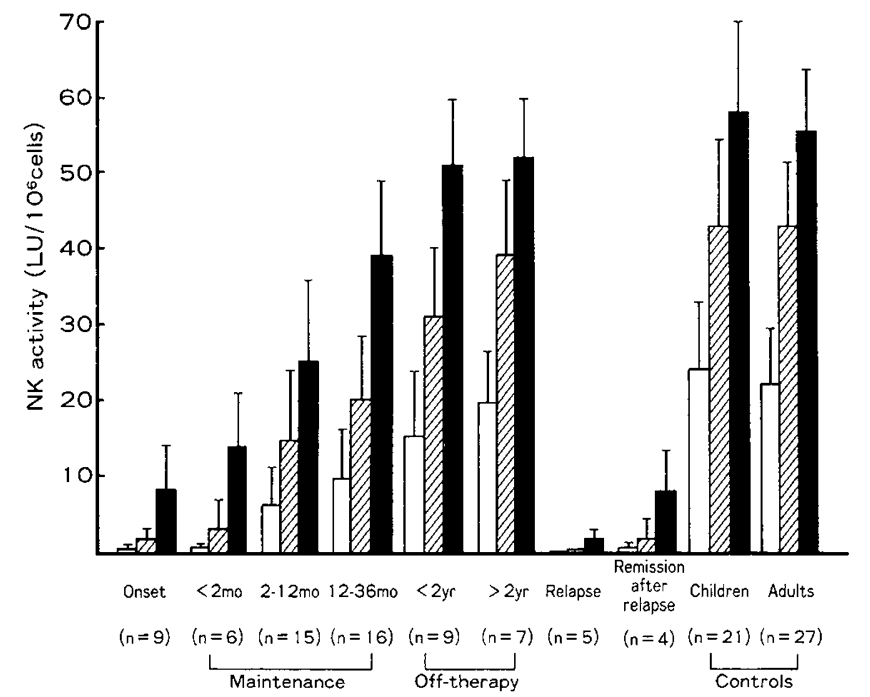

Fig. 1. Endogenous and activated NK activity at different stages of childhood ALL. PBL were incubated for $24 \mathrm{~h}$ with medium alone (open column), $1000 \mathrm{U} / \mathrm{ml} \mathrm{IFN-} \alpha$ (shaded column), or $200 \mathrm{U} / \mathrm{mL}$ IL-2 (closed column) and were evaluated for NK activity. The results were expressed by $\mathrm{LU} / 10^{6}$ cells. A LU was defined as the number of effector cells required for $20 \%$ lysis. The numbers of subjects are shown in parentheses. Data represent mean $\pm \mathrm{SD}$.

values for NK parameters were lower than those in newly diagnosed ALL children.

Although some NK parameters in neuroblastoma were depressed at onset, the depression improved to control levels after the active stage of this disease.

$N K$ activity and NK parameters of $B M C$. Because the bone marrow in ALL children was occupied by leukemic cells at onset and in relapse, we could not determine the NK cytolytic functions of BMC at these stages. The results obtained at the other stages of ALL are shown in Table 3. Although BMC from ALL children had a defect in their NK activity until cessation of the maintenance therapy, the cells from off-therapy ALL children had control levels of NK activity. At the single-cell level, however, the recycling defect of NK cells persisted after completing the therapy for ALL. On the other hand, NK activity and NK parameters in neuroblastoma were not depressed even at the time of onset (Table 3).

Effects of IFN- $\alpha$ and IL-2 on NK parameters. The mechanism(s) of IFN- $\alpha$ or IL-2 enhancement of NK activity was analyzed at the single-cell level (Fig. $2 A-D$ ). IL-2 was different from IFN- $\alpha$ in having an augmentative effect on the binding ability of effector cells. The lytic ability of TBC was enhanced by both IFN- $\alpha$ and IL-2; IL-2 could induce higher levels of lysis than IFN- $\alpha$. Thus, IL-2 could increase the number of cytotoxic cells more efficiently than IFN- $\alpha$. With regard to the recycling ability of cytotoxic cells, there was a marked difference between ALL and neuroblastoma: IL-2 caused a significant enhancement of the recycling in neuroblastoma, whereas this cytokine hardly increased the level of the recycling in childhood ALL.

$L A K$ activity and $L A K$ parameters of $P B L$. As shown in Table 4, a 5-d incubation of PBL with IL-2 could induce the generation of cytotoxicity against NK-insensitive Raji cells in both ALL and neuroblastoma. However, in ALL, the LAK activity expressed as $\mathrm{LU} / 10^{6}$ cells was reduced even after the long-term remission. By using a single-cell assay, ALL children in long-term remission were found to have a defect in the recycling ability of LAK cells, suggesting that the recycling defect is responsible for the continued low LAK activity. On the other hand, in neuroblastoma, only the patients with marrow involvement had reduced LAK activity, whereas at all stages of this disease the LAK cells were almost normal in their cytolytic abilities as determined by the single-cell assay.

The kinetics of LAK parameters showed that the binding and lytic abilities of effector cells and the relative number of cytotoxic cells increased with incubation time; the degrees were similar among all groups (Fig. $2 E-G$ ). However, the responsiveness of the recycling ability was low in ALL: although the recycling ability in neuroblastoma and control children was significantly enhanced by a 3-d incubation, the recycling defect in off-therapy ALL was improved only slightly by prolonged incubation (Fig. 2H).

Kinetics of target cell lysis of effector cells. Because the recycling defect seemed to be a characteristic of NK cells in ALL, the mechanism(s) of the defect was further studied. MRC may reflect the time required to lyse a target cell and the chemotactic mobility. Thus, the lysis mediated by NK cells was examined at 
Table 2. NK activity and NK parameters of peripheral blood lymphocytes

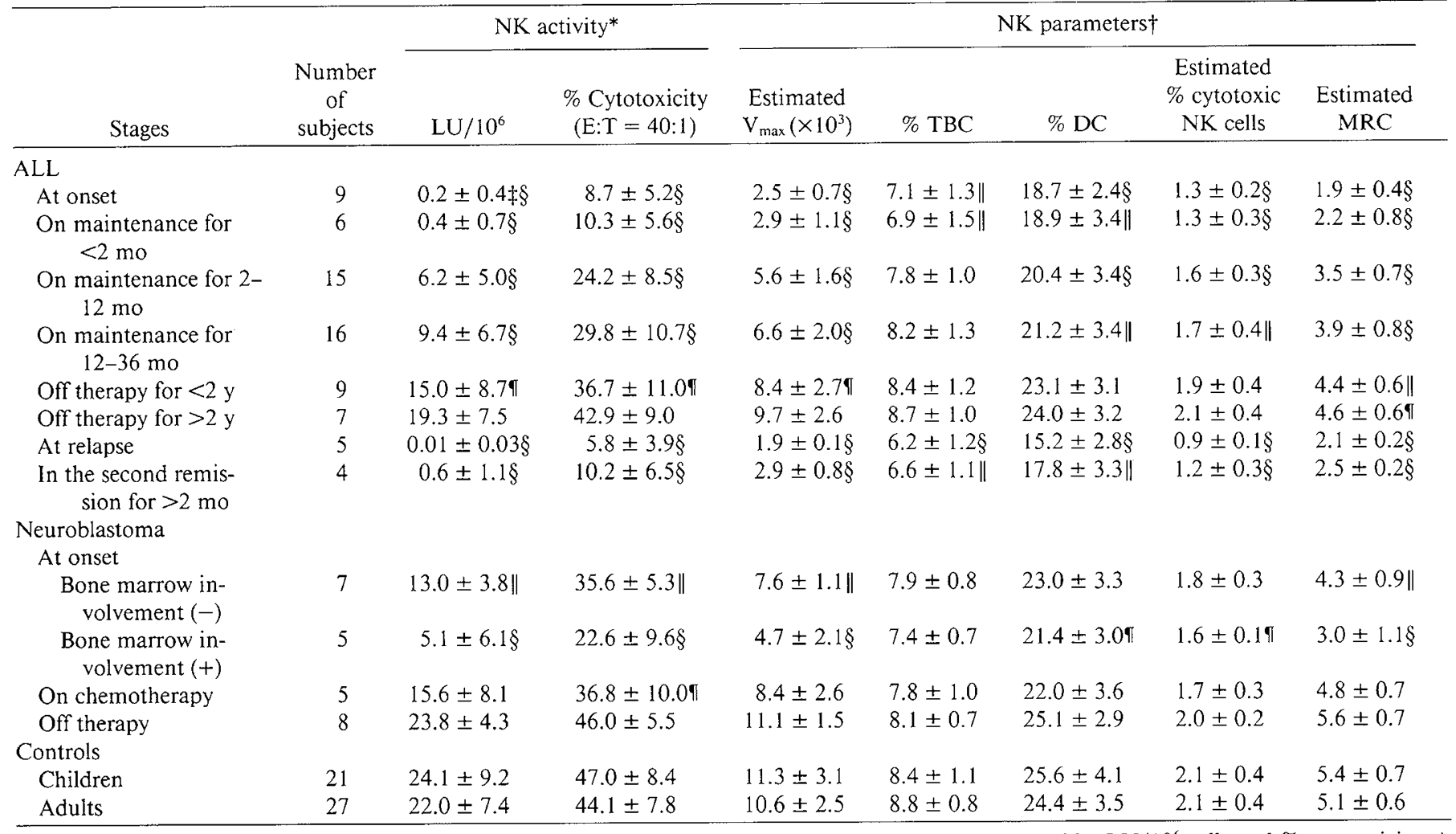

* NK activity was measured in a ${ }^{51} \mathrm{Cr}$-release assay by using $\mathrm{K} 562$ target cells. The results were expressed by LU/10 $0^{6}$ cells and \% cytotoxicity. A LU was defined as the number of effector cells required for $20 \%$ lysis.

$\dagger \mathrm{NK}$ parameters were estimated by using a single-cell cytotoxicity assay in agarose in combination with a ${ }^{51} \mathrm{Cr}$-release assay at an E:T ratio of 5:1.

$\ddagger$ Results are expressed as mean $\pm \mathrm{SD}$.

$\S p<0.001$ as compared to values of control children.

$\| p<0.01$ as compared to values of control children.

If $p<0.05$ as compared to values of control children.

Table 3. NK activity and NK parameters of bone marrow cells

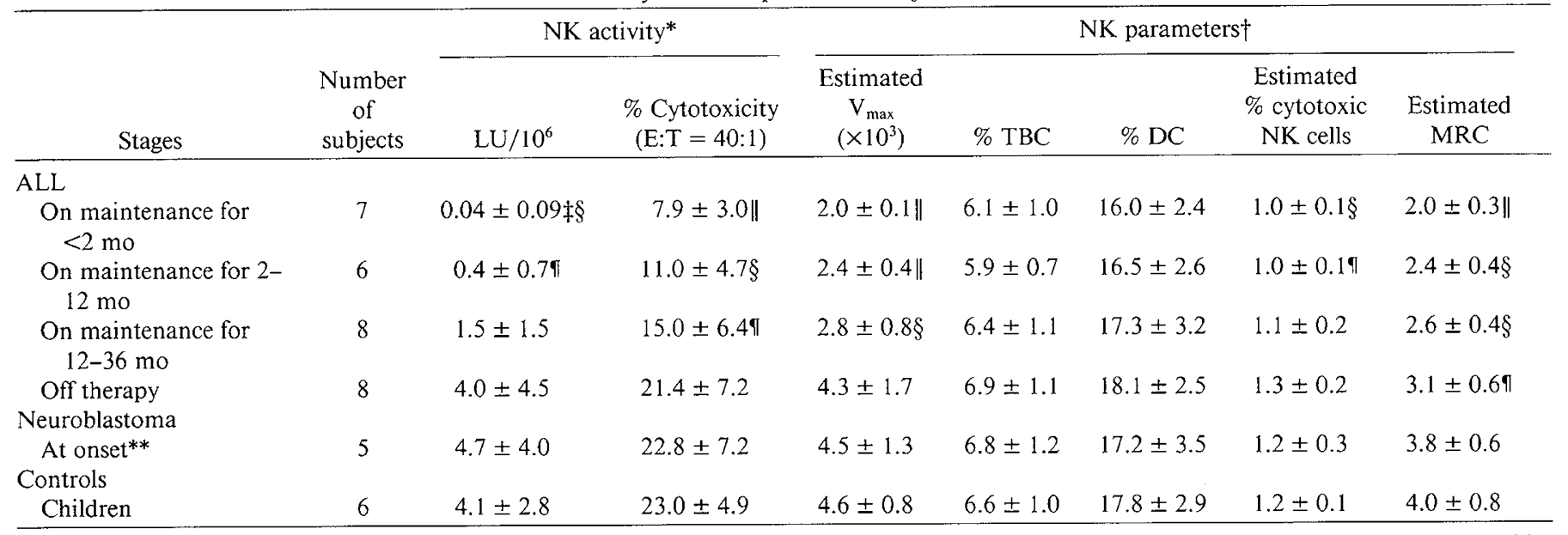

* NK activity of bone marrow mononuclear cells was measured in a ${ }^{51} \mathrm{Cr}$-release assay by using K562 target cells. The results were expressed by LU $/ 10^{6}$ cells and $\%$ cytotoxicity. A LU was defined as the number of effector cells required for $20 \%$ lysis.

$\dagger$ NK parameters were estimated by using a single-cell cytotoxicity assay in agarose in combination with a ${ }^{51} \mathrm{Cr}$-release assay at an $\mathrm{E}$ : $\mathrm{T}$ ratio of 5:1.

$\ddagger$ Results are expressed as mean $\pm \mathrm{SD}$.

$\S p<0.01$ as compared to values of control children.

$\| p<0.001$ as compared to values of control children.

If $p<0.05$ as compared to values of control children.

** The patients had no neuroblastoma cells in their bone marrow. 

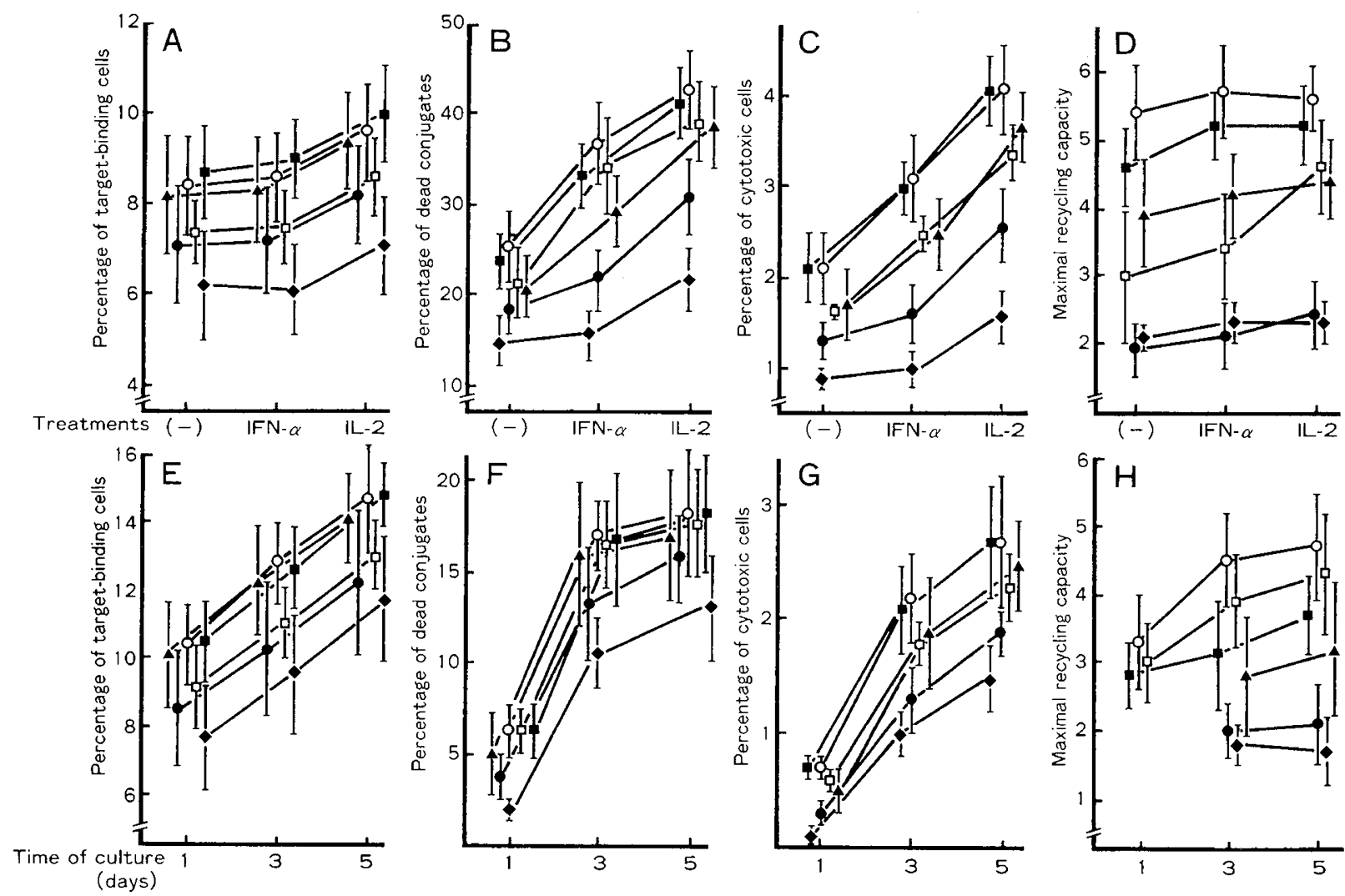

Fig. 2. Effects of IFN- $\alpha$ and IL-2 on NK parameters $(A-D)$ and kinetics of LAK parameters $(E-H)$. PBL were obtained from ALL children at onset $(A-D, n=9 ; E-H, n=7 ; \boldsymbol{\bullet})$, on maintenance for $12-36 \operatorname{mo}(n=16 ; n=7 ; \boldsymbol{\Lambda})$, off therapy for $>2$ y $(n=7 ; n=6 ; \boldsymbol{\square})$, or at relapse $(n=5 ; n$ $=5 ; \diamond)$; neuroblastoma children at onset $(n=5 ; n=5 ; \square)$; and age-matched control children $(n=21 ; n=17 ; 0)$. The neuroblastoma children had neuroblastoma cells in their bone marrow. For determining NK parameters, the PBL were incubated for $24 \mathrm{~h}$ with medium alone, $1000 \mathrm{U} / \mathrm{mL}$ IFN$\alpha$, or $200 \mathrm{U} / \mathrm{mL}$ IL-2. LAK cells were induced by culturing the PBL with $200 \mathrm{U} / \mathrm{mL} \mathrm{IL-2} \mathrm{for} \mathrm{1,} \mathrm{3,} \mathrm{and} 5$ d. Percentage of target-binding cells $(A$ and $E$ ), percentage of dead conjugates $(B$ and $F)$, percentage of cytotoxic cells $(C$ and $G)$, and maximal recycling capacity $(D$ and $H)$ were determined by single-cell and ${ }^{51} \mathrm{Cr}$-release assays using K562 or Raji target cells. Data represent mean \pm SD.

different time points using a single-cell assay. As shown in Figure $3 A$, the lysis in ALL was depressed, especially at early time points; this finding was found even after cessation of the maintenance therapy. At all stages except relapse, there were additional increases in \% DC after $4 \mathrm{~h}$ of incubation. These results indicate the prolongation of target cell lysis as a mechanism of the recycling defect. Although IL-2 increased \% DC in a marked degree at each time point, the resulting values were still low at early time points as compared to those in control children (Fig. 3B).

\section{DISCUSSION}

Growing evidence indicates that endogenous and activated forms of NK cells play an important role in the resistance to leukemia $(1,4,17,18)$. In this respect, several studies have demonstrated that ALL children display low NK activity (6-9). Our present study has confirmed the previous reports: NK activity is greatly depressed at onset, but it increases gradually during remission and finally reaches normal levels; after relapse, it is more severely depressed. The purpose of our study was to analyze the mechanisms of impaired NK cytotoxicity in childhood ALL using a single-cell assay.

First, attention was directed to the number of NK cells. When leukemic cells are not detected in PB, immunophenotypic analysis has shown that the relative numbers of cells with NK-related phenotypes such as CD16, CD56, and CD57 are relatively normal at all stages. Because NK activity usually expresses the cytotoxicity mediated by a given number of lymphocytes, this result suggests that the low NK activity in childhood ALL is not explained by the level of population size. However, the absolute number of NK cells is low at the times of onset, relapse, and the early stage of remission, suggesting that the NK cell defect in this disease is partly explained by a quantitative deficit.

It is possible that the defective NK cytotoxicity may be due to an aberrancy in one or more steps of the lytic cycles (13). The single-cell assay was used to analyze this possibility. At the time of onset, this assay has shown that NK cells are impaired in the binding, lytic, and recycling abilities. Thus, there are multiple defects in the cytolytic function of NK cells at onset of ALL. On the other hand, we have observed in neuroblastoma that the bone marrow involvement results in several functional defects of NK cells. Considering that the bone marrow of ALL children at onset is occupied by leukemic cells, the multiple defects may be a consequence of leukemic cell growth. Because NK cells differentiate probably in bone marrow (19), it seems reasonable to propose that leukemic cell growth has suppressive effects on NK cytotoxicity.

It is noteworthy that ALL children undergoing the maintenance therapy have low NK activity. Although the binding defect is found only at the early stage of the maintenance, the lytic and recycling defects are found throughout the maintenance. The treatment of effector cells with vincristine, L-asparaginase, methotrexate, or 6-mercaptopurine seems to have no suppressive effect on their cytotoxicity in vitro $(6,8)$, but the administration of these agents may exert influence on the differentiation of NK cells in the bone marrow. Furthermore, the treatment with prednisolone decreases NK activity (6); it caused a slight decrease in the binding and marked decreases in the lysis and recycling (data not shown). Therefore, the chemotherapy for ALL may be partly responsible for the low NK activity observed during the maintenance therapy. However, neuroblastoma children on 
Table 4. LAK activity and LAK parameters of peripheral blood lymphocytes

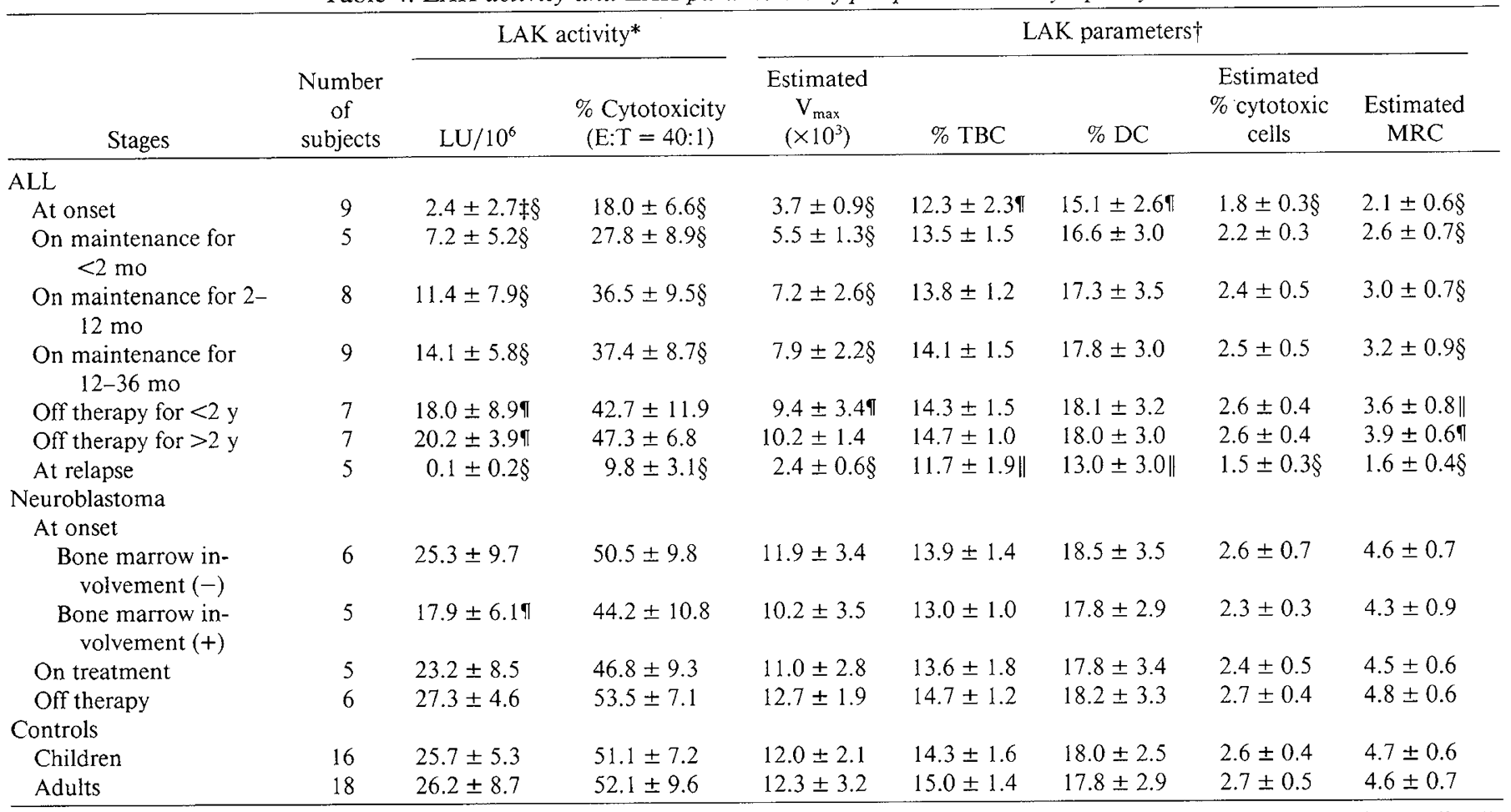

* LAK cells were generated by culturing lymphocytes with IL-2 $(200 \mathrm{U} / \mathrm{mL})$ for $5 \mathrm{~d}$ and were evaluated for the cytotoxicity against Raji cells using a ${ }^{51} \mathrm{Cr}$-release assay. The results were expressed by $\mathrm{LU} / 10^{6}$ cells and \% cytotoxicity. A LU was defined as the number of effector cells required for $20 \%$ lysis.

† LAK parameters were estimated by using a single-cell cytotoxicity in agarose in combination with a ${ }^{51} \mathrm{Cr}$-release assay at an E:T ratio of 5:1.

$\ddagger$ Results are expressed as mean $\pm \mathrm{SD}$.

$\S p<0.001$ as compared to values of control children

$\| p<0.01$ as compared to values of control children.

If $p<0.05$ as compared to values of control children.

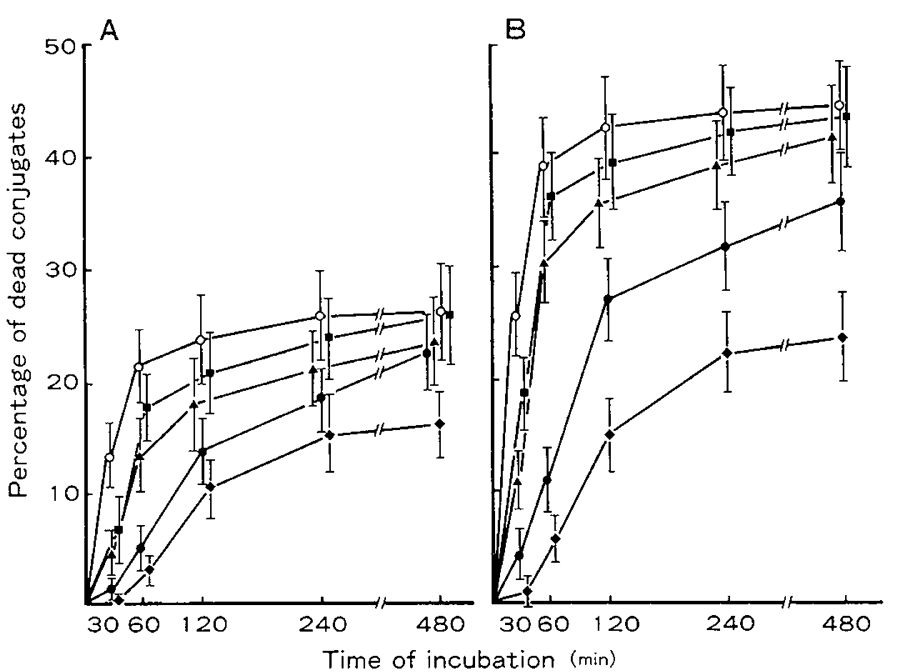

Fig. 3. Kinetics of target cell lysis of effector cells from ALL children. PBL from ALL children at onset $(n=3, \bullet)$, on maintenance for 12-36 mo $(n=4, \Delta)$, off therapy for $>2$ y $(n=4, \boldsymbol{\square})$, or at relapse $(n=3, \diamond)$, and age-matched control children $(n=5, O)$ were incubated for $24 \mathrm{~h}$ with medium alone $(A)$ or $200 \mathrm{U} / \mathrm{mL}$ IL-2 $(B)$. The percentage of dead conjugates was determined at various time points by a single-cell assay using K562 target cells. Data represent mean \pm SD.

chemotherapy had no significant depression in NK cytolytic functions, suggesting that the chemotherapy alone does not have apparent suppressive effect on NK functions.

Considering the possibility that NK cell defects may lead to leukemic growth $(4,17)$, it is noteworthy that ALL children undergoing the maintenance therapy still have functional defects of NK cells. Furthermore, Kosmids et al. (20) have demonstrated that leukemic children in complete remission are highly susceptible to viral infections. In particular, exposure of leukemic children to varicella-zoster virus can result in severe infection with high morbidity and mortality (21). Lopez et al. (22) have reported that NK cells are required for resistance to herpesvirus infections and NK cell deficiencies may be particularly responsible for the severity of these infections. Thus, NK cell defects possibly contribute to susceptibility to severe virus infections during complete remission.

Of great significance is that ALL children in long-term remission are not free from a recycling defect of NK cells. Because the recycling defect is not observed in neuroblastoma treated with chemotherapy, the continued recycling defect in ALL cannot be explained by the effect of its chemotherapy alone; thus, this defect seems to be characteristic of NK cells in ALL. It is known that they have a greater risk of second malignancies, especially leukemia and lymphoma (23). On the other hand, NK cell deficiency is often associated with the development of these diseases $(4,5,17)$. Thus, the long-lasting recycling defect is important as a late effect in childhood ALL. In this regard, the kinetics of target cell lysis has indicated that a prolonged time for NK lysis contributes to the recycling defect.

Our study further demonstrates that after relapse, NK functions are more severely reduced. Once relapse occurs, the second remission can be achieved in fewer cases and the prognosis is not necessarily satisfactory; this may be related, at least in part, to the reduced NK functions.

Because bone marrow has importance in the generation of NK cytotoxicity (19), it is interesting to study NK functions of bone marrow cells. In our study, although BMC in neuroblastoma had 
normal levels of NK activity and NK parameters even at onset, BMC in ALL had a recycling defect at all stages. Based on these findings, NK cells in ALL probably acquire the intrinsic functional defects during differentiation and maturation.

Considering the roles of NK cells in regulation of leukemic cell growth (18) and resistance of viral infections $(1,2,22)$, the correction of NK cell defects is worthy of attention. As demonstrated here, IFN- $\alpha$ and IL-2 can increase NK activity at all stages of ALL. This result suggests that these cytokines may be useful for enhancing the cytotoxicity of NK cells. However, the study on the mechanisms of IFN- $\alpha$ or IL- 2 enhancement using a single cell has revealed that the responsiveness of NK cell recycling to IL-2 is low in ALL as compared to that in neuroblastoma. The low response may also be involved in the recycling defect of NK cells in childhood ALL.

The therapeutic approaches aimed at improving the NK cell defects in ALL possibly contribute to the successful management of this disease. It is known that the incubation with IL-2 results in the generation of LAK cells that are able to lyse autologous leukemic cells $(3,16)$. Thus, the antileukemic effect of LAK cells raises a possibility for their therapeutic application. In our study, although a 5-d incubation with IL-2 could generate LAK activity from PBL in ALL, the LAK cells were slightly depressed in cytotoxicity even after the long-term remission. By using a singlecell assay, the recycling defect of LAK cells was found to be a mechanism of the continued low LAK activity. Because NK cells contribute to the major portion of LAK activity (15), this result provides additional evidence that NK cells in ALL children have a recycling defect.

In this article, we have demonstrated the NK cell recycling defect as a mechanism of impaired NK cytotoxicity in childhood ALL. Because NK cells may play an important role in surveillance against leukemic growth $(1,4,17,18)$ and have the possibility to contribute to the therapy for leukemia $(3,7,16)$, it is noteworthy that NK cells in ALL children have a recycling defect as a functional characteristic.

Acknowledgments. The authors thank Professor Taro Akabane and Associate Professor Atsushi Komiyama for their kind advice and suggestions throughout this study.

\section{REFERENCES}

1. Herberman RB, Ortaldo JR 1981 Natural killer cells: their role in defenses against disease. Science 214:24-30

2. Trinchieri G, Perussia B 1984 Human natural killer cells: biologic and pathologic aspects. Lab Invest 50:489-513

3. Lotzová E, Savary CA, Herberman RB 1987 Induction of NK cell activity against fresh human leukemia in culture with interleukin 2. J Immunol 138:2718-2727
4. Takagi S, Takaku F 1981 Natural killer cell activity and preleukemia. Lancet 2:1178

5. Roder JC, Haliotis T, Klein M, Korec S, Jett JR, Ortaldo J, Herberman RB, Katz P, Fauci AS 1980 A new immunodeficiency disorder in humans involving NK cells. Nature 284:553-555

6. Kawai H 1984 A marked decrease of endogenous and activated natural killer cell activities in childhood acute lymphoblastic leukemia. Acta Paediatr Jpn 26:481-489

7. Mageed AA, Findley HM, Franco C, Singhapakdi S, Alvarado C, Chan WC, Ragab AH 1987 Natural killer cells in children with acute leukemia. Cancer 60:2913-2918

8. Jermy A, Lilleyman JS, Jennings R, Rees RC 1987 Spontaneous natural killer cell activity in childhood acute lymphoblastic leukaemia. Eur J Clin Oncol 23:1365-1370

9. Sørskaar D, Førre $\varnothing$, Lie SO 1989 Increased natural killer cell activity and numbers of Leu-7 and Leu-11b(CD16)-positive cells in bone marrow of children in remission from acute lymphoblastic leukaemia. Scand J Immunol 29:65-72

10. Ullberg M, Jondal M 1981 Recycling and target binding capacity of human natural killer cells. J Exp Med 153:615-628

11. Kawai H, Komiyama A, Aoyama K, Miyagawa Y, Akabane T 1988 Absence of circulating natural killer (NK) cells in a child with erythrophagocytic lymphohistocytosis lacking NK cell activity. Am J Hematol 28:107-1 12

12. Komiyama A, Kawai H, Yamada S, Aoyama K, Yamazaki M, Saitoh H, Miyagawa Y, Akabane T 1985 Impaired natural killer cell recycling in childhood chronic neutropenia with morphological abnormalities and defective chemotaxis of neutrophils. Blood 66:99-105

13. Komiyama A, Kawai H, Yabuhara A, Yanagisawa M, Miyagawa Y, Ota M, Hasekura H, Akabane T 1990 Natural killer cell immunodeficiency in siblings: defective killing in the absence of natural killer cytotoxic factor activity in natural killer and lymphokine-activated killer cytotoxicities. Pediatrics 85:323-330

14. Yabuhara A, Kawai H, Komiyama A 1990 Development of natural killer cytotoxicity during childhood: marked increases in number of natural killer cells with adequate cytotoxic abilities during infancy to early childhood. Pediatr Res 28:316-322

15. Ortaldo JR, Mason A, Overton R 1986 Lymphokine-activated killer cells: analysis of progenitors and effectors. J Exp Med 164:1193-1205

16. Findley HW, Mageed AA, Nasr SA, Ragab AH 1988 Recombinant interleukin2 activates peripheral blood lymphocytes from children with leukemia to kill autologous leukemic cells. Cancer 62:1928-1931

17. Kärre K, Klein GO, Kiessling R, Klein G, Roder JC 1980 Low natural in vivo resistance to syngeneic leukaemias in natural killer-deficient mice. Nature 284:624-626

18. Beran M, Hasson M, Kiessling R 1983 Human natural killer cells can inhibit clonogenic growth of fresh leukemic cells. Blood 61:596-599

19. Hackett J, Tutt M, Lipscomb M, Bennett M, Koo G, Kumar V 1986 Origin and differentiation of natural killer cells. II. Functional and morphological studies of purified NK-1.1+ cells. J Immunol 136:3124-3131

20. Kosmids HV, Lusher JM, Shope TC, Ravindranath Y, Dajani AS 1980 Infections in leukemic children: a prospective analysis. J Pediatr 96:814-819

21. Feldman S, Cox F 1976 Viral infections and haematological malignancies. Clin Haematol 5:311-328

22. Lopez C, Kirkpatrick D, Read SE, Fitzgerald RA, Pitt J, Pahwa S, Ching CY, Smithwick EM 1983 Correlation between low natural killing of fibroblasts infected with herpes simplex virus type 1 and susceptibility to herpesvirus infections. J Infect Dis 147:1030-1035

23. Mosijezuck AD, Ruymann FB 1981 Second malignancy in acute lymphocytic leukemia. Review of 33 cases. Am J Dis Child 135:313-316 